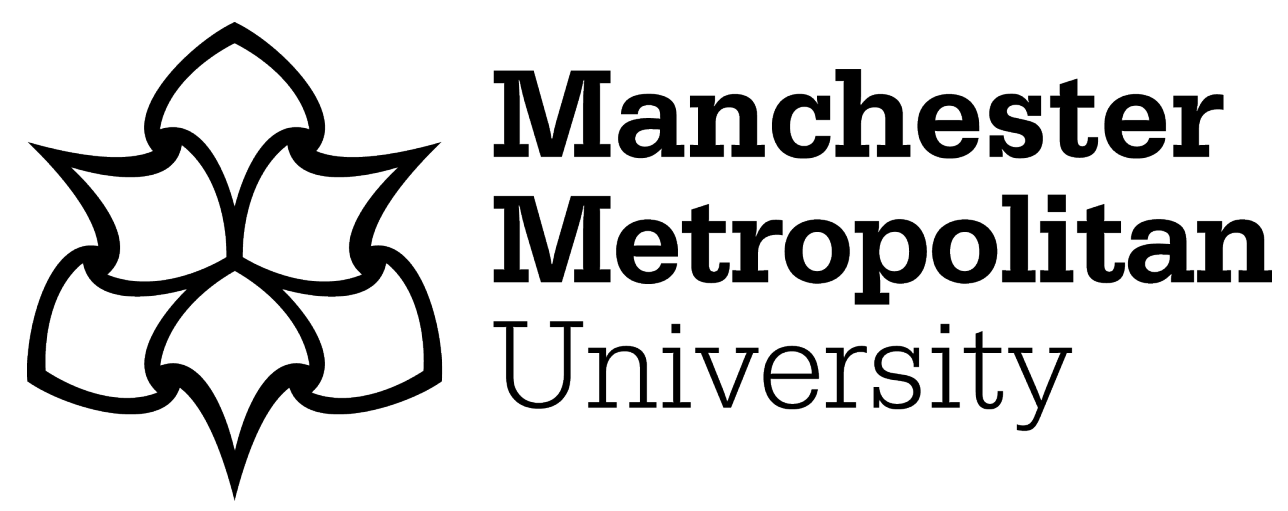

Rajab, F, Liauw, C, Benson, P, Li, L and Whitehead, KA (2017) Production of hybrid macro/micro/nano surface structures on Ti6Al4V surfaces by picosecond laser surface texturing and their antifouling characteristics. Colloids and Surfaces B: Biointerfaces, 160. pp. 688-696. ISSN 0927-7765

Downloaded from: https://e-space.mmu.ac.uk/619266/

Version: Accepted Version

Publisher: Elsevier

DOI: https://doi.org/10.1016/j.colsurfb.2017.10.008

Usage rights: Creative Commons: Attribution-Noncommercial-No Derivative Works 4.0

Please cite the published version 


\section{Highlights}

- Picosecond laser generated surface topographies on titanium were produced

- The surfaces had a range of different macro, micro and nano topographies

- All the laser generated surfaces retained less bacteria than the control surface

- The surfaces were antiadhesive following attachment, adhesion and retention assays

- The Ti2 surface was particularly antiadhesive to bacteria 


\title{
Production of hybrid macro/micro/nano surface structures on Ti6Al4V surfaces by picosecond laser surface texturing and their antifouling characteristics
}

Fatema H. Rajab ${ }^{1}$, Christopher M. Liauw ${ }^{2}$, Paul S. Benson ${ }^{2}$, Lin Li $^{1}$, Kathryn A. Whitehead ${ }^{2 *}$

${ }^{1}$ Laser Processing Research Centre, School of Mechanical, Aerospace and Civil Engineering, The University of Manchester, Manchester, M13 9PL, UK

${ }^{2}$ School of Healthcare Science, Manchester Metropolitan University, Manchester, M1 5GD, $U K$

Corresponding author *To whom correspondence should be addressed. Email: k.a.whitehead@mmu.ac.uk; Tel: +44 (0)161247 1157

\begin{abstract}
The development of surfaces which reduce biofouling has attracted much interest in practical applications. Three picosecond laser generated surface topographies (Ti1, Ti2, Ti3) on titanium were produced, treated with fluoroalkylsilane (FAS), then characterised using Scanning Electron Microscopy (SEM), Energy Dispersive X-ray Spectroscopy (EDX), Raman Spectroscopy, Fourier Transform Infra-Red (FTIR) spectroscopy, contact angle measurements and white light interference microscopy. The surfaces had a range of different macro / micro / nano topographies. Ti2 had a unique, surface topography with large blunt conical peaks and was predominantly a rutile surface with closely packed, self-assembled FAS; this was the most hydrophobic sample (water contact angle $160^{\circ} ; \Delta \mathrm{G}_{\mathrm{iwi}}$ was $-135.29 \mathrm{~mJ}$ $\mathrm{m}^{-2}$ ). Bacterial attachment, adhesion and retention to the surfaces demonstrated that all the laser generated surfaces retained less bacteria than the control surface. This also occurred following the adhesion and retention assays when the bacteria were either not rinsed from the surfaces or were retained in static conditions for one hour. This work demonstrated that picosecond laser generated surfaces may be used to produce antiadhesive surfaces that significantly reduced surface fouling. It was determined that a tri-modally dimensioned surface roughness, with a blunt conical macro-topography, combined with a close-packed
\end{abstract}


fluoroalkyl monolayer was required for an optimised superhydrophobic surface. These surfaces were effective even following surface immersion and static conditions for one hour, and thus may have applications in a number of food or medical industries.

Keywords: Laser surface texture, retention, superhydrophobic, bacteria, anti-adhesive, antifouling.

\section{Introduction}

The development of surfaces which reduce biofouling is of great interest for industrial applications [1]. Biofouling may represent a threat to public health, causing medical device failures or causing infections and diseases [2]. Biofouling may also occur in a wide range of industrial processes and equipment and may result in issues for the marine industry, in water systems [3, 4], and the food processing industry [5].

There are many plants In nature such as the lotus leaf are considered as self-cleaning surfaces that have macro / micro / nano topographies. These surfaces are superhydrophobic with contact angles $\geq 150^{\circ}$, and such surfaces enable a water droplet to roll off with a sliding angle $<10^{\circ}[6]$. The surfaces of these plant leaves exhibit high static contact angles because of the combination of their complex topographical structures with low surface energy wax coatings [7]. The leaf consists of different levels of topographies, including nano $(<0.5 \mu \mathrm{m})$, micro $(>$ $0.5 \mu \mathrm{m}-10 \mu \mathrm{m})$ and macro topographies $(>10 \mu \mathrm{m})$. Water droplets on these surfaces readily sit on the apex of the structures because air fills the valleys between the papillae under the droplet [8].

Modifying the substratum topography, physicochemistry and/or chemistry has been suggested as a means to alter microbial attachment to a surface [9]. Replication of these surfaces may allow their use in different applications, and it may be possible to produce such surfaces that enhance the control of bacteria attachment. Both natural and artificial Taro leaf structures have been shown to reduce bacterial attachment and biofilm formation [10]. 
There are a number of stages that result in bacterial adsorption to a surface; attachment, adhesion and retention. The first stage of bacterial attachment to a surface is driven by physicochemical factors which are influenced by both surface chemistry and topography [11]. In the literature, contradictory results with regard to the influence of hydrophobicity on initial attachment are found [12-14]. The following steps of bacterial adhesion and retention to a surface are dependent on the substratum roughness and topography [11]. Many studies have been carried out to study the effect of surface topography on bacterial retention. However, the exact influence of surface properties on this phenomenon remains poorly understood. Topographic surfaces may be characterised using an average surface roughness value $\left(S_{a}\right)$. Other roughness parameters such as $S_{q}$ (root-mean square roughness) or $S_{p v}$ (peak to valley roughness) may be used to describe surface topographies. However, alongside these measurements it has been suggested that the shape and form of the surface features also needs to be described $[9,11,14,15]$. The effects of these surface properties (chemistry, physicochemistry and topography) are highly confounded and affect one another. It is therefore difficult to separate the effects / contributions of individual factors. Titanium is used in a wide range of medical and industrial applications due to its unique properties such as light weight, biocompatibility, corrosion resistance, ease of fabrication and modification [1618]. Different techniques such as photolithography, moulding, plasma treatment, and lithography have been used to generate different topographies on different surfaces [19]. However, laser induced surface structures may be preferable because they are simple to manufacture, environmentally clean and can be fabricated on different substrates in ambient and non-standard atmospheres [20,21]. Laser surface texturing can be used to produce different topographic structures and has been extensively studied for a range of different applications such as modification of optical properties, wetting properties and in the surface modification of bioimplants [17, 22-25]. 
This study focused on the effect of laser generated titanium surfaces with hierarchical topographical features on bacterial attachment, adhesion and retention.

\section{Material and Methods}

\subsection{Laser surface texture preparation}

Prior to laser treatment, Ti-6Al-4V (Aerocom Metals, UK) sheet of $1 \mathrm{~mm}$ thickness was ultrasonically cleaned by immersion for $10 \mathrm{~min}$ into acetone, ethanol and deionised water. The surface texturing was performed using Edge Wave picosecond laser at a $1064 \mathrm{~nm}$ wavelength $103, \mathrm{kHz}$ repetition rate, $125 \mu \mathrm{m}$ spot size and $10 \mathrm{ps}$ pulse duration in air with no assist gas. The scanning was performed using a parallel line regime. The laser processing parameters were selected to obtain hierarchical topographies. Til was processed using laser parameters of $0.178 \mathrm{Jcm}^{-2}, 10 \mathrm{mms}^{-1}$ and $10 \mu \mathrm{m}$ whilst $0.138 \mathrm{Jcm}^{-2}, 1 \mathrm{mms}^{-1}$ and $10 \mu \mathrm{m}$ was used for Ti2 and $0.178 \mathrm{Jcm}^{-2}, 100 \mathrm{mms}^{-1}$ and $80 \mu \mathrm{m}$ was used in case of Ti3. After the laser treatment, the samples were ultrasonically cleaned with ethanol for 10 min to remove any ablated debris or contamination, and then dried using compressed air. The samples were treated with $1 \% \quad \mathrm{w} / \mathrm{v}$ heptadecafluoro-1,1,2,2-tetrahydro-decyl-1-trimethoxysilane $\left(\mathrm{CF}_{3}\left(\mathrm{CF}_{2}\right)_{7}\left(\mathrm{CH}_{2}\right)_{2} \mathrm{Si}\left(\mathrm{OCH}_{3}\right)_{3}\right)$ in methanol for $2 \mathrm{~h}$ followed by an ethanol rinse, with a final drying period at $80^{\circ} \mathrm{C}$ for $30 \mathrm{~min}$ [26]. The heptadecafluoro-1,1,2,2-tetrahydro-decyl-1trimethoxysilane (Gilest Inc., USA) was used as received and was denoted FAS or fluoroalkylsilane hereafter.

\subsection{Surface characterisation}

\subsubsection{Scanning Electron Microscopy (SEM) and Energy Dispersive X-ray Spectroscopy (EDX)}

The SEM (Philips XL30 FEG-SEM (FEI, Holland) was fitted with Bruker energy dispersive spectroscopy analytical system. $20 \mathrm{kV}$ accelerating voltage and spot size of 3 with full area 
scanning mode were used. X-ray penetration depth was determined to be in the region of 1 $\mu \mathrm{m}-2 \mu \mathrm{m}$.

\subsubsection{Fourier Transform Infra-Red Spectroscopy (FTIR)}

The samples were analysed using a Thermo-Nicolet Nexus FTIR spectrophotometer bench fitted with a Spectra-Tech diffuse reflectance (DRIFTS) cell featuring sliding hemispherical mirrors (Thermo-Fisher, UK). The entire instrument and sample compartment were purged with air that had both water and carbon dioxide removed using a Balaston purge gas generator (flow rate $30 \mathrm{~L} \mathrm{~min}^{-1}$ ). Both background and sample spectra were made up of 164 scans with the resolution set to $4 \mathrm{~cm}^{-1}$. Background spectral data was collected from the FAS treated but otherwise unmodified titanium substrate so that any FAS adsorption in excess of that on the control substrate was observed. The sample was placed on top of a macrosampling cup and positioned such that the area to be analysed was illuminated by the alignment laser at a sample height corresponding to maximum IR throughput. The diameter of the IR beam was approximately $2 \mathrm{~mm}$.

Confirmatory spectra were also run using a Perkin-Elmer Spotlight 200i FTIR microscope, fitted with the standard liquid nitrogen cooled mercury-cadmium telluride detector. The microscope was coupled to a Perkin-Elmer Spectrum Two FTIR bench. Spectra were made of 128 to scans with the resolution set to $4 \mathrm{~cm}^{-1}$. The apertures were set to their maximum size of $800 \mu \mathrm{m} \times 800 \mu \mathrm{m}$. A gold mirror was used to collect the background spectral data. Neither the Spotlight 200i FTIR microscope or the Spectrum two were purged with water and $\mathrm{CO}_{2}$ free air.

\subsubsection{Raman Spectroscopy}

The Raman spectroscopic analysis was carried out on an inVia Raman Microscope (Renishaw, UK) equipped with a $514 \mathrm{~nm}$ laser. The samples were analysed using the $50 \mathrm{X}$ 
objective for an exposure time of $30 \mathrm{~s}$ and three accumulations were taken. Five random areas on each sample were examined. The penetration depth was around $100 \mathrm{~nm}-500 \mathrm{~nm}(\mathrm{n}=5)$.

\subsubsection{Confocal Laser Microscopy}

After the laser treatment, the surfaces were examined using Keyence X200K 3D Confocal Laser Microscope (KEYENCE, USA) using a $150 \mathrm{X}$ objective lens to determine the substratum macro and micro topographies. The instrument control and data analysis were performed using VK analyser software. Values of $S_{a}$ (average surface roughness), $S_{q}$ (rootmean square roughness) and $S_{p v}$ (peak to valley roughness) were recorded for each of the surfaces. Selected line scans were used to determine the shape height, depth and width of the peaks and valleys.

\subsubsection{Atomic Force Microscopy (AFM)}

A Dimension 3100 AFM (Veeco Instruments Inc., UK) was used to examine the surfaces to determine their nanotopographies. Image processing was carried out using Scanning Probe Image Processor (SPIP).

\subsubsection{Determination of surface energy and components using the Van Oss approach}

The surface energies of the laser-textured surfaces were obtained via sessile drop contact angle measurements using an FTA 188 (First Ten Angstroms, Inc., UK) contact angle analyser. The three test liquids were deionised water, formamide (Sigma-Aldrich, UK) and $\alpha$ bromonaphthalene (Sigma-Aldrich, UK) and a droplet size of $6 \mu \mathrm{L}$ was used. Five measurements using the different liquids were performed in triplicate (five drops on each of three samples of each material: $\mathrm{n}=15$ ). After measuring the contact angles of the three test liquids on each of the surfaces, the Van Oss approach was used to determine the surface energy and its components [27]

$\Delta G_{i w i}=-2\left(\sqrt{\gamma_{S}^{L W}}-\sqrt{\gamma_{L}^{L W}}\right)^{2}+4\left(\sqrt{\gamma_{S}^{+} \gamma_{W}^{-}}+\sqrt{\gamma_{S}^{-} \gamma_{W}^{-}}-\sqrt{\gamma_{S}^{+} \gamma_{S}^{-}}-\sqrt{\gamma_{W}^{+} \gamma_{W}^{-}}\right)$ 
where $\gamma^{L W}, \gamma^{+}$and $\gamma^{-}$are, respectively, the Lifshitz-van der Waals component of the surface free energy, the electron acceptor and donor parameters of the Lewis acid-base component $\gamma^{A B}$, where

$$
\gamma^{A B}=2 \sqrt{\gamma^{+} \gamma^{-}}
$$

The subscripts s, w and 1 refer to the substrate, water and the test liquids, respectively.

The contact angle obtained for each test liquid on a given surface and the known values of $\gamma_{1}^{\mathrm{LW}}, \gamma_{1}^{-}$and $\gamma_{1}^{+}$for each test liquid were entered into Eq.(3).

$$
(1+\cos \theta)_{\gamma_{1}}^{\mathrm{TOT}}=2\left(\sqrt{\gamma_{\mathrm{S}}^{\mathrm{LW}} \gamma_{1}^{\mathrm{LW}}}+\sqrt{\gamma_{\mathrm{S}}^{+} \gamma_{1}^{-}}+\sqrt{\gamma_{\mathrm{S}}^{-} \gamma_{1}^{+}}\right)
$$

where $\theta$ is the contact angle and $\gamma^{T O T}=\gamma^{L W}+\gamma^{A B}$.

\subsection{Microbiology}

A single colony of Escherichia coli NCTC 9001 was inoculated in one hundred millilitres of nutrient broth (Oxoid, UK) and incubated with shaking overnight for $24 \mathrm{~h}$ at $37{ }^{\circ} \mathrm{C}$. Following incubation, cells were harvested at $3630 \mathrm{~g}$ for $10 \mathrm{~min}$. Then the harvester cells were washed and re-suspended using $10 \mathrm{~mL}$ sterile distilled water; this was repeated three times. Cells were re-suspended to optical density $(\mathrm{OD})=1.0 \pm 0.1$ at $540 \mathrm{~nm}$ in sterile distilled water. Serial dilutions were used to determine the colony-forming units $\mathrm{mL}^{-1}$ (cfu $\mathrm{mL}^{-1}$ ) which were $2.83 \times 10^{9} \mathrm{cfu} \mathrm{mL}^{-1}$.

\subsubsection{Spray with wash (attachment) and Spray (adhesion) assays}

Replicates of the surfaces were attached using adhesive gum to a stainless steel tray. ). In a class 2 flow hood, the surfaces were placed vertically. Bacterial suspension (OD $1.0 @ 540$ $\mathrm{nm}$ ) was placed into the spray reservoir of an airbrush (Badger, Shesto, UK), propelled by a $600 \mathrm{~mL}$ liquid gas canister (Esselte Letraset Ltd, UK). Over a $10 \mathrm{~s}$ period, the bacterial suspension was sprayed over the substrate from a distance of $10 \mathrm{~cm}$. Immediately after spraying, the samples were divided into two sets each containing three coupons, one set was 
laid horizontally without any movements and left to dry. The other set was rinsed with sterile distilled water using a wash bottle (with $3 \mathrm{~mm}$ nozzle diameter) at $45^{\circ}$ to the surface and dried for $1 \mathrm{~h}$ at room temperature. The samples were prepared for SEM imaging $(\mathrm{n}=15$ for each replicate, 5 per coupon).

\subsubsection{Retention assay}

The laser textured surfaces and the control one (without texturing) were placed into sterile Petri dishes. $25 \mathrm{~mL}$ of cell suspension at $\mathrm{OD}=1.0$ was added and the surfaces were incubated for $1 \mathrm{~h}$ without agitation. The surfaces were washed gently with distilled water using a water bottle at a $45^{\circ}$ angle, with a $3 \mathrm{~mm}$ nozzle. The surfaces were dried in a laminar flow hood for $1 \mathrm{~h}$ and then the samples were prepared for SEM examination. The experiments were performed in triplicate. Five images of each surfaces incubated bacterial were taken. Then the number of attached cells for each image was counted $(n=15$ for each replicate, 5 per coupon).

\subsubsection{Preparation of samples for scanning electron microscopy}

After drying the samples bearing cells, they were immersed in a $4 \%$ glutaraldehyde (Agar, UK) solution at $4{ }^{\circ} \mathrm{C}$ overnight. Samples were thoroughly rinsed with distilled water using a wash bottle with a $3 \mathrm{~mm}$ nozzle diameter, at $45^{\circ}$ to the surface and dried for $1 \mathrm{~h}$ at room temperature in a class 2 flow hood. The samples were immersed sequentially in each of the following ethanol (Sigma-Aldrich, UK) / water mixtures $(30 \%, 50 \%, 70 \%, 90 \%$ and $100 \%$ $\mathrm{v} / \mathrm{v}$ ethanol) for $10 \mathrm{~min}$ and dried for $1 \mathrm{~h}$. Imaging was performed using a Supra 40VP (Carl Zeiss Ltd., UK) at 15,000 X magnification. The quantifications were made in the equivalent area $=0.0713 \mathrm{~cm}^{2}$. For each microbiology test, three replicate substrata were tested for each assay, and individual substrata were each tested three times $(n=9)$. Five different areas were imaged using SEM for each coupon making the final number cell counts $n=45$ for each surface/assay. 


\subsubsection{Statistics}

The statistical analysis of data was carried out using a two-sample student's t-test. The data were considered significant when $p<0.05$. Error bars indicate the standard deviation of the data.

\section{Results}

\subsection{Characterisation of Laser Textured Surfaces}

Picosecond laser ablation was used to fabricate self-organized structures on titanium Surface topographies were generated with different roughness ranging from low roughness $(390 \mathrm{~nm})$ using high-speed ablation $\left(100 \mathrm{~mm} \mathrm{~s}^{-1}\right)$ to moderate roughness $(660 \mathrm{~nm})$ using moderate speed $\left(10 \mathrm{~mm} \mathrm{~s}^{-1}\right)$ ablation a high surface roughness $(1.1 \mu \mathrm{m})$ following the use of low speed laser ablation $\left(1 \mathrm{~mm} \mathrm{~s}^{-1}\right)$.

FTIR spectra (obtained using the purged Nexus with DRIFTS cell with the FAS treated control background) of the textured titanium surfaces areas were obtained (Fig. 1). It was evident that the Ti2 surface showed relatively strong absorption peaks at $1240 \mathrm{~cm}^{-1}, 1205 \mathrm{~cm}^{-}$ 1, $1150 \mathrm{~cm}^{-1}, 1135 \mathrm{~cm}^{-1}$ and $1113 \mathrm{~cm}^{-1}$. The latter are assignable to C-F stretching vibrations (Table 1) from the adsorbed FAS. Weaker absorption bands at $1368 \mathrm{~cm}^{-1}, 1330 \mathrm{~cm}^{-1}$, may be assignable to $\mathrm{C}-\mathrm{H}$ deformation vibrations of the FAS, and the weaker bands at $1067 \mathrm{~cm}^{-1}$ and $1020 \mathrm{~cm}^{-1}$ may be due to Si-O bending of the condensed FAS surface coating. The Ti1 surface showed substantially weaker C-F stretching peaks at $1238 \mathrm{~cm}^{-1}, 1203 \mathrm{~cm}^{-1}$ and 1146 $\mathrm{cm}^{-1}$. The Ti3 surface showed no absorptions in the DRIFTS spectrum. The data obtained from the FTIR microscope (gold mirror background; data not shown) confirmed the presence of $\mathrm{C}-\mathrm{F}$ absorptions on $\mathrm{Ti} 2$ and $\mathrm{Ti} 1$, but could only resolve a very weak $\mathrm{C}-\mathrm{F}$ stretching absorption on the Ti3 surfaces and an even weaker one on the FAS treated control surface. The C-F absorption on the latter two substrates was so weak that the symmetric and asymmetric CF-F stretching vibrations were merged into one broad peak. In the case of Ti2 
the intensity and sharpness of the C-F absorptions may imply close-packed adsorption and self-assembled heptadecafluoro-1,1,2,2-tetrahydro-decyl groups.

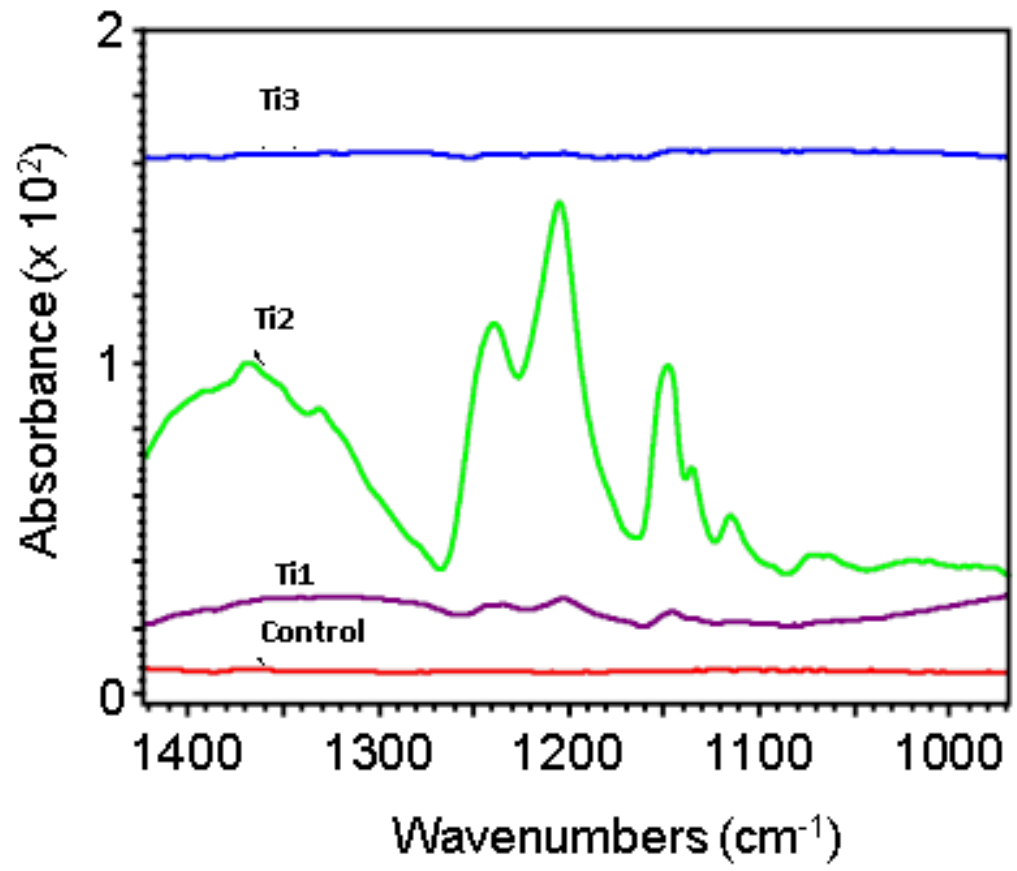

Fig.1. DRIFTS spectra of Control, Ti1, Ti2 (showing strong C-F bands due to prolific interaction with the fluorosilane) andTi3. The background used was the unmodified titanium substrate. 
Table 1 FTIR peak assignments.

\begin{tabular}{ll}
\hline $\begin{array}{l}\text { Peak Position } \\
\left(\mathrm{cm}^{-1}\right)\end{array}$ & Assignment \\
\hline 1368 and 1330 & $\begin{array}{l}\text { C-H deformation of FAS, the band at } 1330 \mathrm{~cm}^{-1} \\
\text { may be due to the methylene bonded to the } \mathrm{Si}\end{array}$ \\
1240 & $\begin{array}{l}\mathrm{CF}_{2}-\mathrm{F} \text { degenerate asymmetric stretching } \\
1205\end{array}$ \\
CF-F symmetric stretching \\
1150 & CF-F asymmetric stretching \\
1135 and 1113 & CF $-F$ symmetric stretching \\
1067 and 1020 & Si-O-Si bending of condensed FAS \\
\hline
\end{tabular}

Energy dispersive X-Ray data (Table 2) showed that the overall compositions of the surfaces following laser treatment were titanium with oxygen, nitrogen and aluminium with some fluorine and vanadium. The atomic fluorine levels for Control, Ti1, Ti2, Ti3 were 2.6, 2.4, 5.5, 2.7 At \%, respectively. Since the X-ray penetration depth was about $1 \mu \mathrm{m}-2 \mu \mathrm{m}$ it was unlikely for fluorine to be found below the surface of the substrates. The O:Ti ratios from EDX were $0.50,0.69$ and 0.21 for Ti1, Ti2 and Ti3, respectively. The higher O:Ti ratio obtained for Ti2 may indicate a substantially larger amount of $\mathrm{TiO}_{2}$ at the surface. $\mathrm{TiO}_{2}$ is likely to also feature $\mathrm{Ti}-\mathrm{OH}$ bonds that are reactive with the FAS. It may therefore be envisaged that the FAS may interact prolifically with the Ti2 surface. As the O:Ti ratio for the Ti3 surface was the lowest recorded, there is likely to be only a small amount of Ti-OH resulting in the lower level of FAS adsorption observed. The samples also contained some nitrogen; the N:Ti atomic ratios were $0.29,0.29$ and 0.33 for Ti1, Ti2 and Ti3, respectively. This suggests that hybrid / intermediate $\left(\mathrm{TiO}_{2}\right)_{\mathrm{x}} \mathrm{N}_{\mathrm{y}}$ and $\mathrm{TiO}_{\mathrm{x}} \mathrm{N}_{\mathrm{y}}$ structures may be present at the surfaces. 
Table 2 Atomic percentages of elements in the Control, Ti1 to Ti3 and O:Ti and N:Ti ratios detected by EDX (Standard deviations are in parenthesis). Note all samples have been treated with FAS.

\begin{tabular}{ccccc}
\hline \multirow{2}{*}{$\begin{array}{c}\text { Element } \\
\text { or ratio }\end{array}$} & \multicolumn{4}{c}{ Element amount (At\%) } \\
\cline { 2 - 5 } $\mathrm{C}$ & $0(0)$ & $1.94(0.10)$ & $2.40(0.11)$ & $2.39(0.07)$ \\
$\mathrm{N}$ & $0(0)$ & $14.61(0.89)$ & $12.73(0.59)$ & $18.82(1.03)$ \\
$\mathrm{O}$ & $0(0)$ & $24.66(1.07)$ & $30.19(0.26)$ & $11.89(1.81)$ \\
$\mathrm{F}$ & $2.58(0.29)$ & $2.44(0.67)$ & $5.45(0.65)$ & $2.66(0.27)$ \\
$\mathrm{Al}$ & $9.40(0.45)$ & $6.13(0.47)$ & $5.25(0.14)$ & $6.71(0.29)$ \\
$\mathrm{Si}$ & $0.21(0.10)$ & $0.12(0.03)$ & $0.10(0.02)$ & $0.14(0.01)$ \\
$\mathrm{Ti}$ & $87.35(0.70)$ & $49.71(0.27)$ & $43.69(1.41)$ & $57.15(1.80)$ \\
$\mathrm{V}$ & $0.37(0.02)$ & $0.29(0.06)$ & $0.17(0.02)$ & $0.23(0.00)$ \\
\hline $\mathrm{O}: \mathrm{Ti}$ & - & 0.50 & 0.69 & 0.21 \\
$\mathrm{~N}: \mathrm{Ti}$ & - & 0.29 & 0.29 & 0.33 \\
\hline
\end{tabular}

The Raman spectra (Fig. 2a) provided further insight into the surface chemistry of the substrates. The penetration depth of the Raman system used was ca. $100 \mathrm{~nm}-500 \mathrm{~nm}$ into the Ti based substrates and can, therefore, be regarded as more chemically surface specific. It should be noted that the Raman spectra of all the samples showed broad band envelopes (ca. 100 to $1000 \mathrm{~cm}^{-1}$ ) with various smaller peaks within the broad band envelopes indicating many superimposed broad and weak peaks and thus a rather disordered structure. The five replicates for each sample also showed some variability, particularly for Ti1 where only three out of the five replicates indicated a clearly resolved $A 1 g$ mode for the Rutile polymorph of $\mathrm{TiO}_{2}$ at ca. $610 \mathrm{~cm}^{-1}$. All five replicates for Ti2 showed a readily resolvable Rutile $A 1 g$ mode. The Ti2 surface was, therefore, more homogeneously Rutile-like in nature, hence possibly 
explaining the prolific adsorption of the FAS. Pure Rutile should also show an Eg mode at $447 \mathrm{~cm}^{-1}$. In both Ti1 and Ti2, the nearest peak to the latter was at varying positions between ca. $418 \mathrm{~cm}^{-1}$ and $439 \mathrm{~cm}^{-1}$. The $E g$ mode for the Anatase polymorph at $144 \mathrm{~cm}^{-1}$ (usually 10 times more intense than the other Raman bands for this polymorph) was perhaps notable by its absence, though the shoulder at ca. $129 \mathrm{~cm}^{-1}$ may be related to this mode and could perhaps indicate the presence of some Anatase-like structures. In pure Rutile, there is also a multi-phonon band at $237 \mathrm{~cm}^{-1}$. In the Til surface, the nearest band to this spectrum was at ca. $260 \mathrm{~cm}^{-1}$; in three of the five replicates this band is the strongest in the spectra. The nearest peak to this Rutile multi-phonon band in $\operatorname{Ti} 2$ is at ca. $284 \mathrm{~cm}^{-1}$. The presence of hybrid structures such as $\left(\mathrm{TiO}_{2}\right)_{\mathrm{x}} \mathrm{N}_{\mathrm{y}}$ and $\mathrm{TiO}_{\mathrm{x}} \mathrm{N}_{\mathrm{y}}$ may explain the unusually placed Raman bands. The Ti3 surface did not show any Rutile assignable Raman bands, the barely discernible shoulder at ca. $127 \mathrm{~cm}^{-1}$ may be due to a low level of Anatase-like structures. The strongest band on the Ti3 surface was at ca. $254 \mathrm{~cm}^{-1}$ and may well be assignable to $\mathrm{TiO}_{\mathrm{x}} \mathrm{N}_{\mathrm{y}}$ inclusions and the broad shoulder at ca. $500 \mathrm{~cm}^{-1}$, supports this. Due to the relatively high intensity of the highly convoluted metal oxide related Raman peaks in the 100 to $1000 \mathrm{~cm}^{-1}$ region, Raman peaks assignable to the FAS could not be observed, even in the case of the Ti2 surface.

The different laser treatments on the surfaces resulted in changes in the colour of the surfaces of the samples (Fig. 2b). The Ti1 and Ti2 surfaces potentially demonstrated the presence of rutile, with a greater amount observed on the Ti2, hence the darker surfaces. The Ti3 surface was gold in colour, which may have been due to the presence of TiNO hybrids. These may have been related to the changes in the different levels of oxidation and nitrogen produced due to the laser patterning process. 

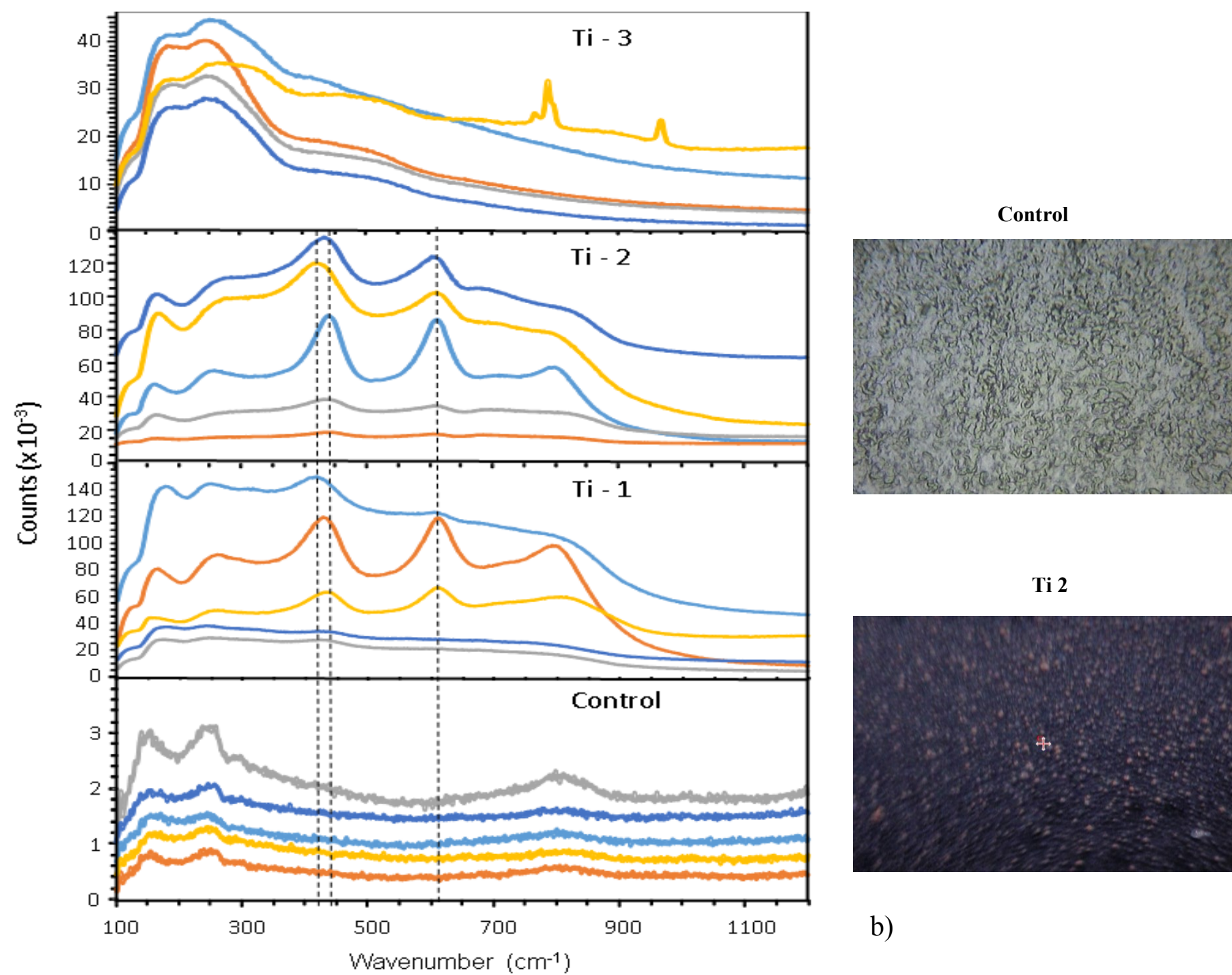

Ti 1

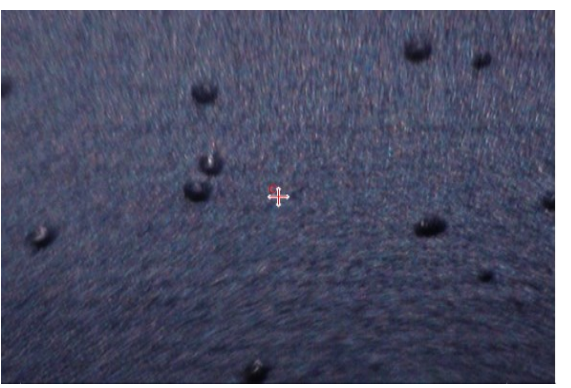

Ti 2

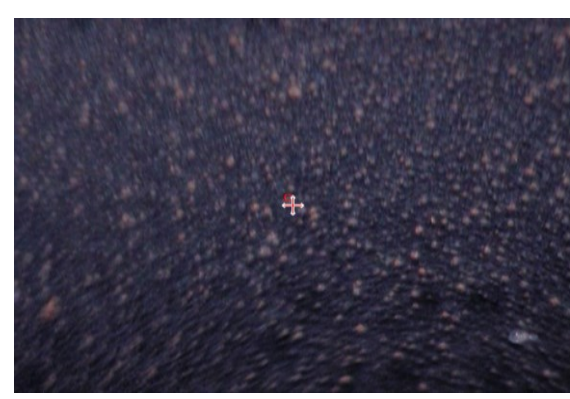

b)

a) Area 1 -Area 2 Area 3 - Area 4 Area 5

Fig.2.(a) Micro-Raman spectra of Control, Ti1, Ti2, and Ti3. The two dotted ordinates at ca. $420 \mathrm{~cm}^{-1}$ and $440 \mathrm{~cm}^{-1}$, highlight the variability of the Rutile $E g$ mode in Ti1 and Ti2. The dotted ordinate at ca. $615 \mathrm{~cm}^{-1}$ highlights the Rutile $A 1 g$ mode. (b) Colour changes of the surfaces. 
SEM images, confocal laser microscope and AFM images of the surfaces demonstrated that the surface had been laser ablated to produce a range of different regular surface features at the macro / micro scale (Fig. 3a). The control surface which had a shot finished irregular surface with convex pits (Fig. 3a (Control)) demonstrated surface valley widths of $2.1 \pm 0.6$ $\mu \mathrm{m}$ and depths of $0.3 \pm 0.02 \mu \mathrm{m}$ whilst the heights of the surface features were $0.3 \pm 0.1 \mu \mathrm{m}$ and $2.2 \pm 0.6 \mu \mathrm{m}$ wide. The Til surface (Fig. 3a (Ti 1)) demonstrated surface features that were long and oval in length with striations in between the surface features. These had peak heights of $0.2 \pm 0.04 \mu \mathrm{m}$ and widths of $0.6 \pm 0.06 \mu \mathrm{m}$, and valley depths and widths of $0.2 \pm$ $0.04 \mu \mathrm{m}$ and $0.8 \pm 0.2 \mu \mathrm{m}$ respectively. The Ti2 surface (Fig. 3a (Ti2)) demonstrated the largest overall surface features that were generally rounded but with a non-uniform circumference and had peak heights ranging from $3 \pm 0.3 \mu \mathrm{m}$ and peak widths of $9.7 \pm 0.8$ $\mu \mathrm{m}$. The valley depth and width for this surface was $2.7 \mu \mathrm{m} \pm 0.4$ and $9.6 \pm 0.5 \mu \mathrm{m}$ respectively. The Ti3 surface (Fig. 3a (Ti3)) demonstrated smaller oval, long shaped surfaces that almost looked to have a rippled effect. The feature heights and widths of the peaks ranged from $0.2 \pm 0.03 \mu \mathrm{m}$ to $0.6 \pm 0.07 \mu \mathrm{m}$, whist the valley depths and widths ranged from $0.2 \pm 0.01 \mu \mathrm{m}$ to $0.6 \pm 0.1 \mu \mathrm{m}$ respectively. In summary, the Ti2 substratum had the greatest surface features. The nano-features of the laser etched surfaces was characterised using AFM (Fig. 3a). The results showed that the nano-features for the control and Ti2 surface were more rounded in shape than for the Til or Ti3 surfaces. The line profile of these surfaces demonstrated that the maximum (peaks width / height, valleys width / height) of Control, Ti1, Ti2 and Ti3 were, respectively, (1.7 / 0.4, 3.0 / 0.3), (1.4 / 0.8, $1.1 / 0.3),(2.5 / 0.9,3.3 / 0.8)$ and $(1.0 / 0.3,0.9 / 0.2)$. Once again the surface features for the Ti2 surface in terms of the peak width and height and valley width and depth were of the largest sizes even at the nanoscale. The roughness values for the surfaces demonstrated that the control surface had the lowest $S_{a}$ value $(0.29 \mu \mathrm{m})$ of all the samples, and there was a significant difference 
between the $S_{a}$ value for the latter and Ti1 $(0.52 \mu \mathrm{m})$ and Ti2 $(1.38 \mu \mathrm{m})$ surfaces (Fig. $\left.3 \mathrm{~b}\right)$. The $S_{q}$ values for the laser ablated Ti1 and Ti2 surfaces were also significantly greater than the control. The $S_{p v}$ (peak to valley roughness) value obtained for Ti2 $(9.37 \mu \mathrm{m})$ was significantly higher than the control $(3.28 \mu \mathrm{m})$ and $\mathrm{Ti} 3(3.73 \mu \mathrm{m})$. 

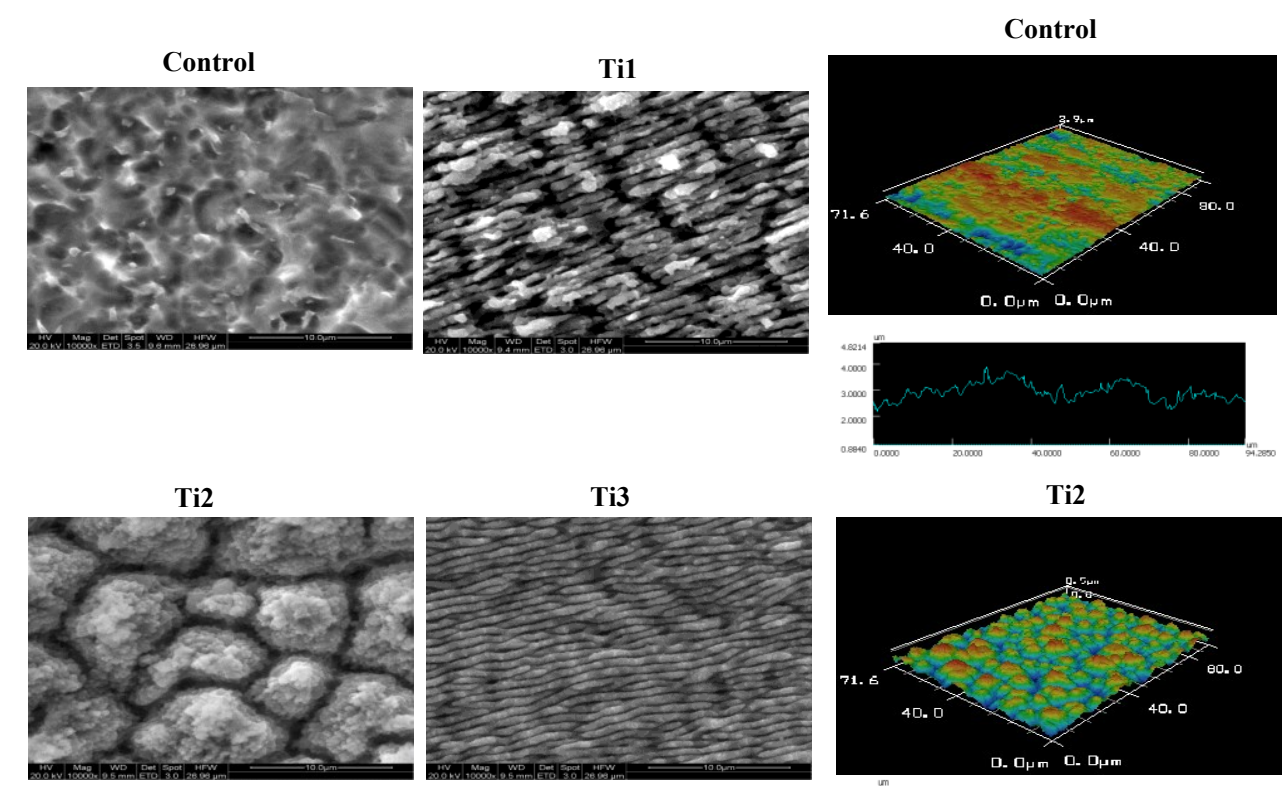

a)

SEM images
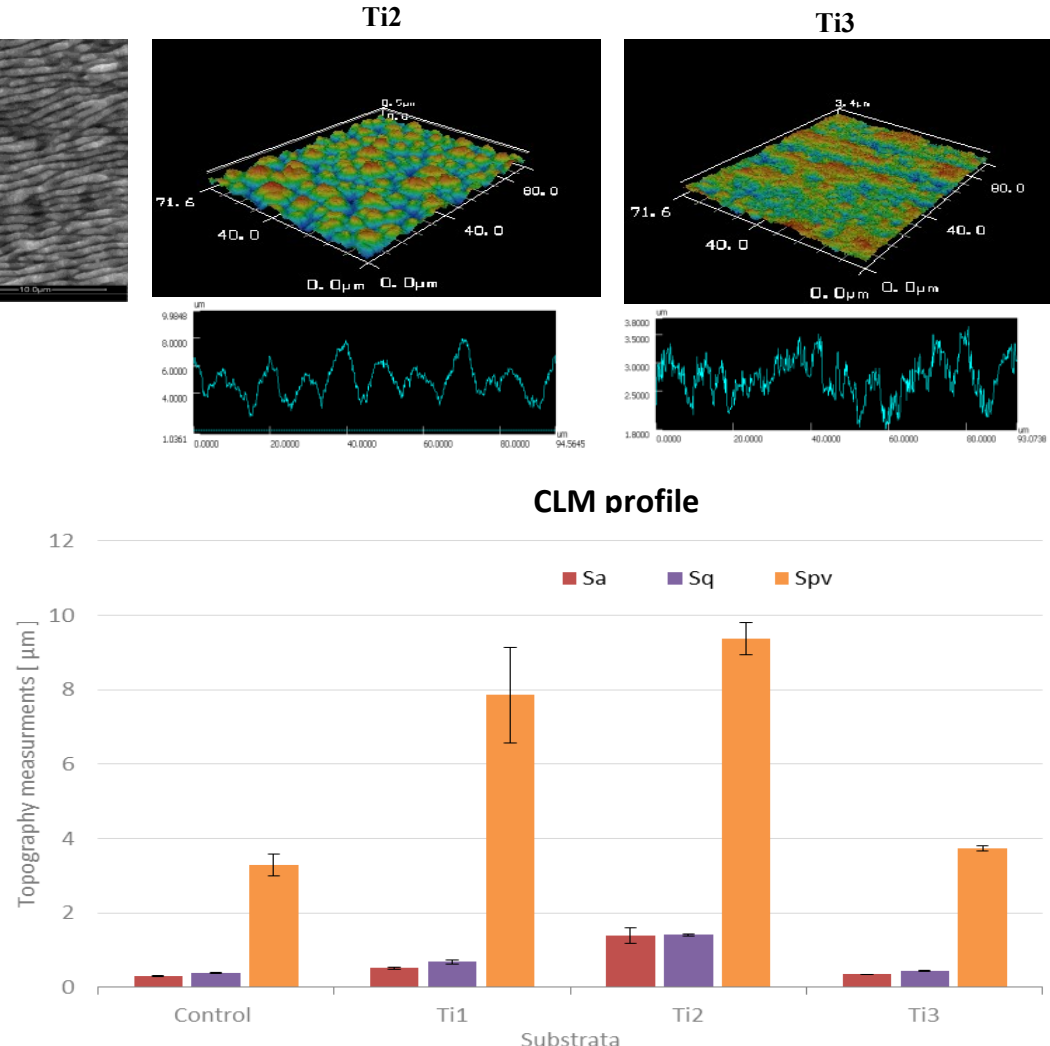

b)

Fig.3. (a) SEM images, confocal laser microscope and AFM profiles of laser produced surfaces and (b) $S$ values using confocal laser microscope of laser produced surfaces compared with the unmodified substrate. Error bars demonstrate the standard deviations from the mean. 
The surface energy data demonstrated that although all the surfaces produced were hydrophobic, the Ti2 surface was, by a significant margin, the most hydrophobic (water contact angle $=160^{\circ}, \Delta \mathrm{G}_{\mathrm{iwi}}=-135.29 \mathrm{~mJ} \mathrm{~m}^{-2}$ ), and yielded the lowest recorded values for all of the surface energy components determined (Table 3). The Ti1 surface was the least hydrophobic surface $\left(\Delta \mathrm{G}_{\mathrm{iwi}}=-68.98 \mathrm{~mJ} \mathrm{~m}^{-2}\right)$, and control surface had the highest surface energy component values recorded with the lest water contact angle. The electron donating component $\left(\gamma^{-}\right)$was greatest for the control surface.

Table 3. Water contact angle and physicochemistry results for surfaces $\left(\mathrm{mJ} \mathrm{m}^{-2}\right)$.

\begin{tabular}{|c|c|c|c|c|c|c|c|}
\hline & $\begin{array}{l}\text { Water } \\
\text { contact } \\
\text { angle }\end{array}$ & $\Delta \mathrm{G}_{i w i}$ & $\gamma_{s}$ & $\gamma_{s}^{L W}$ & $\gamma_{\mathrm{s}}^{\mathrm{AB}}$ & $\gamma_{\mathrm{s}}^{+}$ & $\gamma_{\mathrm{s}}^{-}$ \\
\hline Control & 102.74 & -80.04 & 27.16 & 26.49 & 0.67 & 0.23 & 0.48 \\
\hline Til & 150.48 & -68.98 & 7.86 & 6.33 & 1.52 & 3.34 & 0.17 \\
\hline Ti2 & 160.00 & -135.29 & 0.21 & 0.21 & 0.01 & 0.01 & 0.01 \\
\hline Ti3 & 135.76 & -75.39 & 10.47 & 9.36 & 1.11 & 1.52 & 0.20 \\
\hline
\end{tabular}

\subsection{Microbiology}

Following the bacterial assays (Fig. 4a) it was determined that following the spray with wash assay, that simulated bacterial attachment to the surface, there was no significant difference in the bacterial counts attached on all the surfaces including the control surface (Fig. 4b). However, following the spray assays which do not have a rinse step, similar to an adhesion assay, the number of adhered cells was significantly different on all the surfaces with the least number of cells being adhered on Ti2 (8) followed by the Ti3 surface (17) and then Ti1 surface (29). There were significantly more cells adhered on the control surface (142). Following the retention assays, the control (197) again retained significantly greater numbers 
than the laser ablated surfaces. The Ti2 surface again had the least number of cells retained (10) followed by the Ti3 (23) and finally the Ti1 surface (28). 

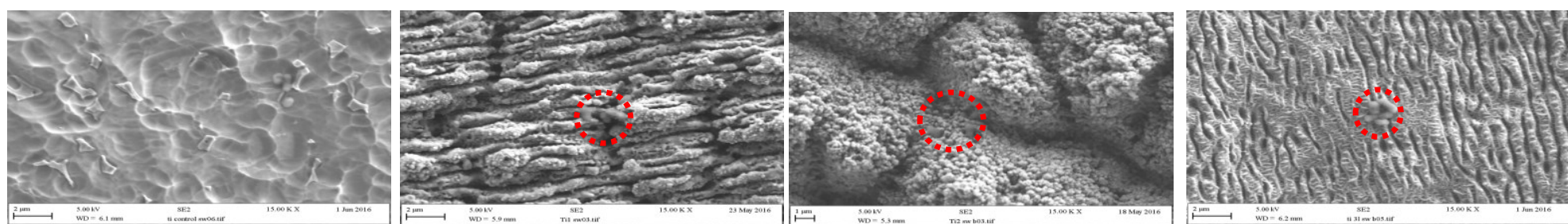

Adh
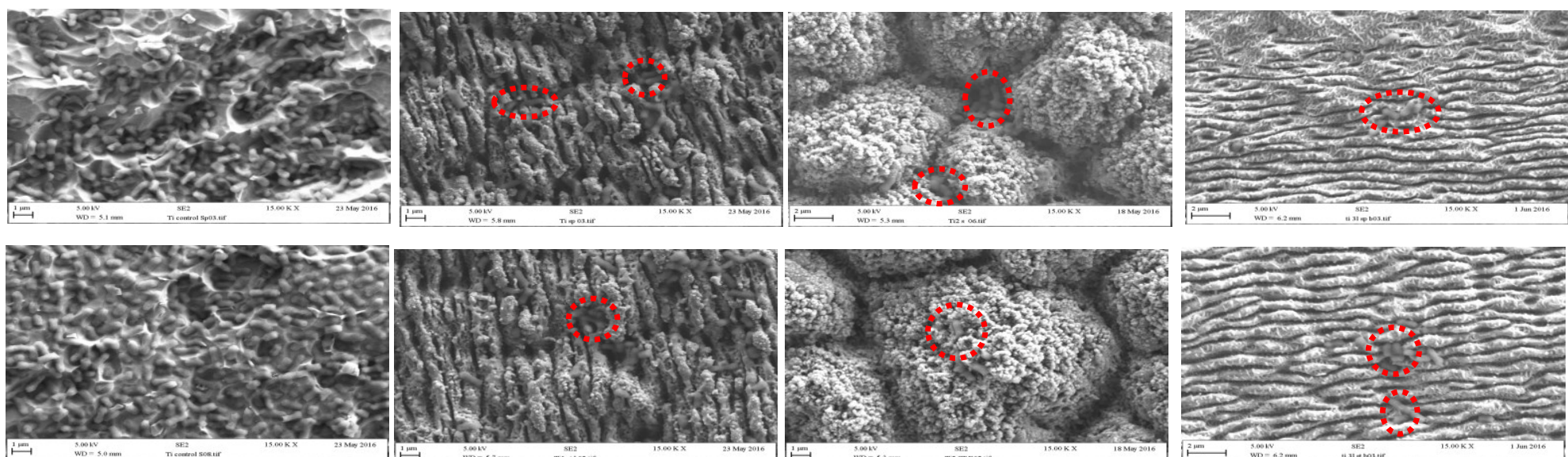

Control

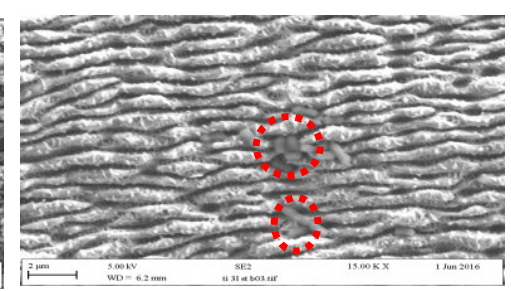

Ti3

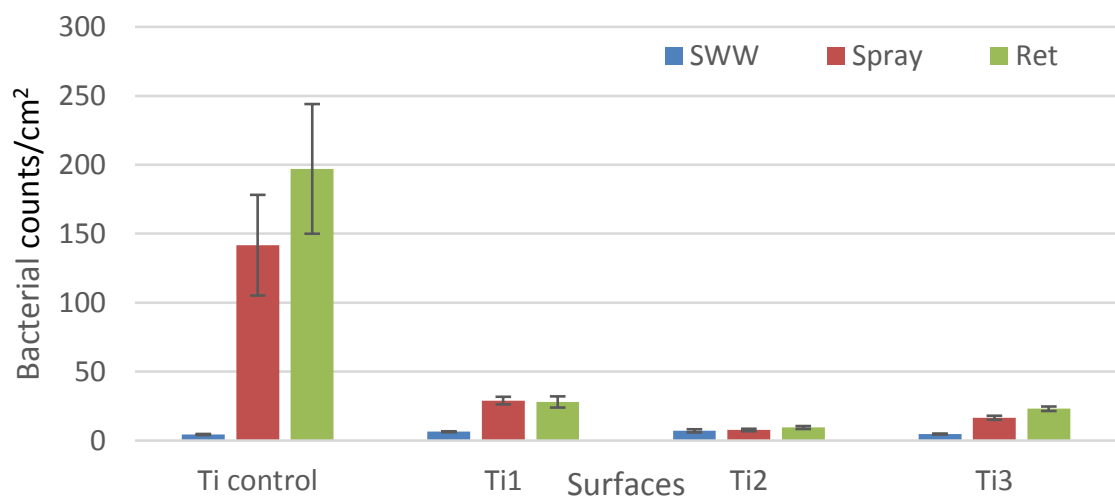

Fig.4. (a) Scanning Electron Microscopy of laser produced surfaces following attachment (Att), adhesion (Adh) and retention (Ret) assays on each surface and (b) Numbers of bacteria retained on the surfaces following attachment (SWW), adhesion (Spray) and retention assays (Ret). Error bars demonstrate the standard deviations from the mean. 


\section{Discussion}

\subsection{Laser surface treatment}

An understanding of how surface properties affect the attachment, adhesion and retention of bacteria helps in designing or modifying the surfaces to discourage bacterial fouling. In this work, Ti6Al4V was chosen as a substrate due to their high tensile strength, good biocompatibility, resultantly the presence of osseointegration, high tensile strength and wide range of applications [28, 29]. Different surface structures were produced on the Ti6Al4V surface depending on the laser treatment parameters used. During ultrashort laser exposure, a significant proportion of the laser energy is absorbed by the free electrons resulting from a thermalization process [30]. At sufficient laser fluence, surface modification, ablation and alterations can take place. In this case, the thermal diffusion effect cannot be neglected [31]. The change of surface morphology and roughness of the laser textured surfaces is related to the change in laser scanning parameters and physiothermal properties of the substrate being treated.

Pulse energy, the extent of line overlapping and the number of pulses per spot affected the generation of different macro / micro / nano structures the on Ti6Al4V surfaces. Pulse overlapping in the direction of scanning, was estimated by [32],

$$
\text { pulse overlapping } \%=\left(1-\frac{\text { speed }}{\text { repitition rate } * \text { spot size }}\right) * 100
$$

and line overlapping in the direction perpendicular to the scanning direction was estimated by [32],

line overlapping $\%=\left(1-\frac{\text { hatch distance }}{\text { spot size }}\right) * 100$

In our study, pulse overlapping was estimated to be $99.2 \%, 99.92 \%$ and $99.99 \%$ at scan speeds of $100 \mathrm{~mm} \mathrm{~s}^{-1}, 10 \mathrm{~mm} \mathrm{~s}^{-1}$ and $1 \mathrm{~mm} \mathrm{~s}^{-1}$ respectively. Line overlapping was estimated to be $36 \%$ and $92 \%$ at respective hatch distances of $80 \mu \mathrm{m}$ and $10 \mu \mathrm{m}$. Pulses per spot were 
estimated to be $\sim 129\left(100 \mathrm{~mm} \mathrm{~s}^{-1}, 80 \mu \mathrm{m}\right), 1290\left(10 \mathrm{~mm} \mathrm{~s}^{-1}, 10 \mu \mathrm{m}\right)$ and $12900\left(1 \mathrm{~mm} \mathrm{~s}^{-1}, 10\right.$ $\mu \mathrm{m})$ (the respective scan speeds and hatch distances are in parenthesis).

The laser ablation of the surfaces changed their composition resulting in a range of colours. Titanium and its alloys react readily with oxygen and nitrogen [33]. The reaction with oxygen is the most problematic whereas nitrogen is normally regarded as negligible [34]. Langdale et al., treated commercially pure titanium with a pulsed Nd:YAG laser $(2-17 \mathrm{kHz}$ frequency, 2 $-50 \mathrm{~mm} \mathrm{~s}^{-1}$ traverse speed) [35]. The authors concluded that although layer thickness may have an effect, the different colours produced corresponded mainly to different titanium oxides. Perez del Pino et al., used a Nd:YAG laser, $(30 \mathrm{kHz}$ frequency, $567 \mathrm{~W}$ mean power, 25-300 mm s $\mathrm{m}^{-1}$ ) and confirmed these results [36]. Additionally, a greater range of oxides was found to form at higher specific energies (defined as laser power / (traverse speed $\mathrm{x}$ beam diameter)). However, a later study by the same authors, comparing the colours obtained from anodising and laser treating titanium, concluded that light interference phenomenon within an upper $\mathrm{TiO}_{2}$ surface layer was the mechanism in both cases [37]. Thus in agreement in our work, when irradiated with white light, the oxide surface reflects only part of the incident photons; the remaining part undergoes refraction inside the oxide and is subsequently reflected by the metal surface resulting in a range of colours $[38,39]$. Rutile $\mathrm{TiO}_{2}$, which is normally obtained at high temperatures such as $800{ }^{\circ} \mathrm{C}$, and held by most authors to be responsible for the interference colours seen on the surfaces, is clearly present. According to the Raman spectra, only the Ti1 and Ti2 surfaces possessed resolvable surface rutile and these were the darkest samples (Ti1 very dark grey and $\mathrm{Ti} 2$ virtually black) indicating $\mathrm{TiO}_{\mathrm{x}}$ surface layers perhaps more than $200 \mathrm{~nm}$ in thickness. The O:Ti ratios (by EDX (penetration depth $1 \mu \mathrm{m}$ to $2 \mu \mathrm{m}$ ) for these samples was 0.50 and 0.69 for Ti1 and Ti2 surfaces, respectively; the higher O:Ti ratio for Ti2 may be indicative of a thicker $\mathrm{TiO}_{\mathrm{x}}$ layer. $\mathrm{Ti} 3 \mathrm{did}$ not show any resolvable surface rutile by Raman spectroscopy and the O:Ti ratio (by EDX) 
was only 0.21 . The yellow - brown colour may therefore arise from TiNO hybrids since TiN is gold in colour and the N:Ti ratio (by EDX) of this sample was slightly higher than for the other samples. Furthermore, Raman spectroscopy tentatively supported the presence of $\mathrm{TiO}_{\mathrm{x}} \mathrm{N}_{\mathrm{y}}$ species. Gyorgy et al., concluded that during pulsed (300 ns) Nd:YAG laser irradiation of $\mathrm{Ti}$ under ambient conditions, oxidation proceeded from $\mathrm{TiO}$ present in the early stage of the irradiation, through $\mathrm{Ti}_{2} \mathrm{O}_{3}$, until the formation of the $\mathrm{TiO}_{2}$ rutile phase at a high number of pulses [40]. From the latter, the presence of Rutile on the Ti1 and Ti2 surfaces was consistent with the greater overall laser energy input used during the production of these surfaces. The greater laser energy input produced a heat accumulation effect that resulted in the different structures and varying levels of $\mathrm{TiO}_{\mathrm{x}}$ production. It may be suggested that the increased $\mathrm{TiO}_{2}$ on this surface increased the level of FAS adsorption. Using a higher scanning speed of $10 \mathrm{~mm} \mathrm{~s}^{-1}$ to produce the Ti1 surface, the extent of overlapping was quite high but lower than that estimated using $1 \mathrm{~mm} \mathrm{~s}^{-1}$ and therefore, the thermal effect was relatively low, which resulted in the generation of structures with a lower surface roughness. This structure was characterised as a Laser Induced Periodic Surface Structure (LIPSS) since it had linear valleys with rounded elongated features. The formation of the narrow peaks was due to overheating liquid explosion, followed by rapid cooling and re-solidification [41]. The less defined Raman peaks observed in Ti1 may be an effect of the surface heterogeneity since the SEM image for Til surface showed some ablation/oxidation as well as laser induced periodic surface structures. It may be that the brighter jagged features on top of the ridges were the oxidised particles from the overheating liquid explosion, whereas the other features of the Ti1 surface may be somewhat less oxidised.

In case of Ti2, which was prepared using $1 \mathrm{mms}^{-1}$ and $10 \mu \mathrm{m}$ hatch distances, the extent of overlapping was high in both directions, resulting in high intensity laser irradiation over a small surface area which in turn may have resulted in enhancement of the nearfield. 
Following the first pulse, as the laser fluence was low, re-solidified particles formed. The fluence of the next pulse and next pass may be enhanced due to a nearfield enhancement mechanism $[42,43]$. The absorption of a greater proportion of reflected laser energy led to increased energy deposition and local overheating of the material, thus causing fusion of the metal to occur at the same time as ablation $[42,43]$. The topography resulting from the latter was found to consist of regular rounded surface peaks. The rounded structure was covered by submicron features which were formed as a result of sintering of particles of ablated substrate [44]. The topography of the Ti3 surface was consistent with a high scan speed and hatch distance resulting in the lowest laser ablation energy input investigated. Therefore, the surface structure produced featured rounded ridges with linear valleys in between. LIPSS or ripple formation has been extensively studied to explain the interaction of fs lasers with metals [45]. It has been suggested that formation of such topography relies on the fluence being approximately equal to or slightly greater than the threshold fluence, which in turn affects the polarisation of incident light [45]. Its formation is thought to be related to laser induced surface instabilities and the interference between incident light waves and reflected or scattered light waves which influence the surface roughness [46].

Analysis of the surface features determined that the surface with the largest topographies and most rounded surface features (Ti2) demonstrated the greatest hydrophobicity and there was correlation between surface energy, and its components, and the surface roughness. The increased surface hydrophobicity of the Ti2 surface may be due to the greater O:Ti ratio on this sample. As determined by Raman spectroscopy, the position of the $E g$ mode was dependent on the O:Ti ratio and the presence of defects and intermediate phases containing nitrogen [47]. In the agreement, Parker et al., demonstrated the O:Ti ratio in Ti2 was closer to 2.0 and that for Til which was closer to 1.9 [47]. The EDX confirmed the higher O:Ti ratio of Ti2 and the overall higher O:Ti ratios estimated from the Rutile $E g$ peak position were due 
to the surface selectivity of the Raman spectroscopy. Thus, as the surface of Ti2 was closer to that of pure Rutile there is a greater chance of forming a close packed monolayer of adsorbed FAS.

Surface energy is an intrinsic property of materials. Low surface energy molecules include primarily methylated and fluorinated carbons, with surface energy decreasing in the following manner: $-\mathrm{CH}_{2}-.-\mathrm{CH}_{3},-\mathrm{CF}_{2}-.-\mathrm{CF}_{2} \mathrm{H},-\mathrm{CF}_{3}$ [48]. The lowest surface energy of any readily available solid is $6.7 \mathrm{~mJ} \mathrm{~m}^{-2}$, based on a hexagonal closed alignment of $-\mathrm{CF}_{3}$ groups on the surface, which gives a water contact angle of $119^{\circ}$ on a smooth surface. Therefore, according to the Wenzel equation [48] a rougher surface is required if higher water contact angles are to be obtained. In our work, the Ti2 surface with its very low $\Delta \mathrm{G}_{\text {iwi }}$ and water contact angle of $160^{\circ}$ is entirely consistent with this effect. There is a strong possibility that the fluoroalkyl tails of the FAS on the Ti2 surface were in a close packed selfassembled monolayer which gave a hexagonal closed alignment of $-\mathrm{CF}_{3}$ groups on the surface; this latter effect, combined with the bimodal surface topography led to the low $\Delta \mathrm{G}_{\mathrm{iwi}}$ and the low microbial adhesion recorded. The formation of a vertically adsorbed monolayer of fluoroalkyl chains on the Ti2 surface is also was supported by the combined EDX and FTIR data for Ti3 and Ti1 surfaces. Whilst the fluorine content of Ti2 was the highest of all the samples, it was only slightly more than twice as high as that of the Ti1 and Ti3 surface. From the mild FAS treatment conditions, it is reasonable to assume that the fluorine observed by EDX must be part of the FAS. The maximum absorbance of the C-F stretching bands of the Ti2 surface was more than 20 times higher than those for Ti1 and Ti3. If the FAS was adsorbed vertically on the latter two substrates, the C-F stretching band absorbance would be about half that observed for Ti2. This is clearly not the case. An explanation may be that the vibration of the fluoroalkyl chains was suppressed by flat adsorption on the Ti1 and Ti3 substrates. This may occur more readily if the laser treatment gives rise to nano-porosity of 
the surface and subsequent entrapment of the FAS in pores particularly if the fit is tightly adjacent since this will suppress the bond vibration. Entrapment of the FAS in pores (or perhaps at the bottom of the valleys of the surface topography) should also have a limited effect on the physicochemical data.

\subsection{Microbiology}

The process of biofouling on a surface begins with microbial attachment, which is influenced by physicochemical forces, followed by adhesion and retention which are influenced in part by topographical factors. Superhydrophobic surfaces are also known to reduce bacterial attachment to a surface, but since the terms attachment adhesion and retention are used interchangeably, elucidation of data by others can be sometimes difficult. Several studies have been carried out to investigate the effect of regular micro or nano-topographies as grooves, squared-features, pits or 'shark-skin', on bacterial retention [9, 17]. Ma et al., demonstrated the importance of hierarchical / bimodal surface roughness that can lead to trapping of the air between dual-scale features and a significant reduction in contact area between the bacteria surface and the substrate thereby reducing the bacteria retention on surfaces[10,49]. Our results suggest that the combination of the laser etched topography which produced large rounded features, the surface chemistry (form of $\mathrm{TiO}_{2}$ present on the surface), which influenced the uptake of FAS and hence physicochemistry on the surface, resulted in the greatest antiadhesive surface Ti2 being produced. An important point is that surfaces that replicate the Lotus effect rely on the minimal attachment of a water droplet on the surface. The rolling action of such a water droplet removes dirt and debris from the surface as it travels. However, in our work, it has been demonstrated that even when the cells were sprayed on and not washed off (spray assay) or the surfaces were incubated under static conditions for an hour and then washed that the surface retained a significantly lower number of cells when compared to the control surface. The use of such surfaces under static 
conditions, or that did not require a washing step in order to increase their hygienic status could be applied to a wide range of novel applications where the prevention of biofouling is crucial.

In our study, it was observed that bacterial cells were retained in surface valleys or grooves, only a few cells were apparent on the tops of ridges and bumps. This was due to the potentially greater contact area in the valleys and the natural gravitational desire to settle in them. Once settled in the valleys the cells are also protected from shear flow (hydrodynamic) forces, as experienced during washing. The dimensions of the valley, i.e. width, wall angle and the radius at the bottom, will influence the contact area and the amount of bacterial retention; the latter will be favoured when contact area is maximised, for example when a rod shaped bacterial cell fits snugly into a steep-sided groove [50]. Bacterial fouling on surface topographies has been extensively studied; however, there is no general conclusion concerning the effect of surface topography on bacterial retention. However, this in part may be due to the range of topographies (nano $<0.5 \mu \mathrm{m}$, micro $0.5 \mu \mathrm{m}-10 \mu \mathrm{m}$ and macro $>10$ $\mu \mathrm{m})$ examined. This is further complicated by the varying chemistry and chemical inhomogeneity (particularly Ti1) of the surfaces. Some have reported that the retention of microorganism increased with increasing the surface roughness [51]. With increasing surface roughness of the correct size scale, the contact area between the surface of the microorganism and the substrate increases, which may enhance the attachment [52]. However, others concluded that there was no correlation between surface roughness and bacteria retention [53]. Our results, which featured surfaces with hierarchical surface topography, i.e. welldefined bimodality between macro, micro and nano scale features, showed that bacterial attachment, adhesion and retention was lower for the laser treated surfaces that demonstrated the largest surface features and the greatest surface hydrophobicity. Thus, these results suggest that a delicate interplay of all three surface parameters (chemistry, topography and 
physicochemistry) need to be optimised to ensure the production of the most antiadhesive surface.

\section{Conclusions}

This study showed that laser etched surfaces produced surface properties that reduced bacterial adhesion and retention. It was determined that a tri-modally dimensioned surface roughness, with a blunt conical macro-topography, combined with a close-packed fluoroalkyl monolayer was required for an optimised superhydrophobic surface. The combination of the surface chemistry, topography and physicochemistry resulted in a superior anti-adhesive surface even under static inoculation conditions. This laser surface structuring approach, combined with the addition of a fluoroalkyl monolayer, may prove to be an important strategy for the development of antiadhesive surfaces used in static conditions to reduce the issues of biofouling in a range of medical and industrial settings.

\section{References}

[1] K. Whitehead, P. Benson and J. Verran, Developing application and detection methods for Listeria monocytogenes and fish extract on open surfaces in order to optimize cleaning protocols, Food and Bioproducts Processing, 93 (2015) 224-233.

[2] M.R. Parsek and P.K. Singh, Bacterial biofilms: an emerging link to disease pathogenesis, Annual review of microbiology, 57 (2003) 677-701.

[3] M. Schultz, J. Bendick, E. Holm and W. Hertel, Economic impact of biofouling on a naval surface ship, Biofouling, 27 (2011) 87-98.

[4] H.-C. Flemming, Biofouling in water systems-cases, causes and countermeasures, Applied microbiology and biotechnology, 59 (2002) 629-640.

[5] R. Van Houdt and C.W. Michiels, Biofilm formation and the food industry, a focus on the bacterial outer surface, Journal of Applied Microbiology, 109 (2010) 1117-1131.

[6] Y.Y. Yan, N. Gao and W. Barthlott, Mimicking natural superhydrophobic surfaces and grasping the wetting process: a review on recent progress in preparing superhydrophobic surfaces, Advances in colloid and interface science, 169 (2011) 80-105.

[7] B. Bhushan, Bioinspired structured surfaces, Langmuir, 28 (2012) 1698-1714.

[8] T. Wang, L. Chang, B. Hatton, J. Kong, G. Chen, Y. Jia, D. Xiong and C. Wong, Preparation and hydrophobicity of biomorphic $\mathrm{ZnO}$ /carbon based on a lotus-leaf template, Materials science \& engineering. C, Materials for biological applications, 43 (2014) 310-316.

[9] K.A. Whitehead, J. Colligon and J. Verran, Retention of microbial cells in substratum surface features of micrometer and sub-micrometer dimensions, Colloids and Surfaces B: Biointerfaces, 41 (2005) 129-138. 
[10] J. Ma, Y. Sun, K. Gleichauf, J. Lou and Q. Li, Nanostructure on taro leaves resists fouling by colloids and bacteria under submerged conditions, Langmuir, 27 (2011) 1003510040.

[11] K.A. Whitehead and J. Verran, The effect of surface topography on the retention of microorganisms, Food and Bioproducts Processing, 84 (2006) 253-259.

[12] M.S. Chae, H. Schraft, L.T. Hansen and R. Mackereth, Effects of physicochemical surface characteristics of Listeria monocytogenes strains on attachment to glass, Food microbiology, 23 (2006) 250-259.

[13] P. Chavant, B. Martinie, T. Meylheuc, M.-N. Bellon-Fontaine and M. Hebraud, Listeria monocytogenes LO28: surface physicochemical properties and ability to form biofilms at different temperatures and growth phases, Applied and environmental microbiology, 68 (2002) 728-737.

[14] H.D. Mortensen, K. Gori, L. Jespersen and N. Arneborg, Debaryomyces hansenii strains with different cell sizes and surface physicochemical properties adhere differently to a solid agarose surface, FEMS microbiology letters, 249 (2005) 165-170.

[15] K.A. Whitehead, J. Colligon and J. Verran, The production of surfaces of defined topography and chemistry for microbial retention studies, using ion beam sputtering technology, International biodeterioration \& biodegradation, 54 (2004) 143-151.

[16] S.F. Lamolle, M. Monjo, S.P. Lyngstadaas, J.E. Ellingsen and H.J. Haugen, Titanium implant surface modification by cathodic reduction in hydrofluoric acid: surface characterization and in vivo performance, Journal of Biomedical Materials Research Part A, 88 (2009) 581-588.

[17] E. Fadeeva, V.K. Truong, M. Stiesch, B.N. Chichkov, R.J. Crawford, J. Wang and E.P. Ivanova, Bacterial retention on superhydrophobic titanium surfaces fabricated by femtosecond laser ablation, Langmuir, 27 (2011) 3012-3019.

[18] K.S. Brammer, S. Oh, J.O. Gallagher and S. Jin, Enhanced cellular mobility guided by TiO2 nanotube surfaces, Nano letters, 8 (2008) 786-793.

[19] J. Gold, B. Nilsson and B. Kasemo, Microfabricated metal and oxide fibers for biological applications, Journal of Vacuum Science \& Technology A, 13 (1995) 2638-2643.

[20] A. Gaggl, G. Schultes, W. Müller and H. Kärcher, Scanning electron microscopical analysis of laser-treated titanium implant surfaces - a comparative study, Biomaterials, 21 (2000) 1067-1073.

[21] G. Pető, A. Karacs, Z. Pászti, L. Guczi, T. Divinyi and A. Joób, Surface treatment of screw shaped titanium dental implants by high intensity laser pulses, Applied Surface Science, 186 (2002) 7-13.

[22] A.Y. Vorobyev and C. Guo, Direct femtosecond laser surface nano/microstructuring and its applications, Laser \& Photonics Reviews, 7 (2013) 385-407.

[23] S. Schlie, E. Fadeeva, J. Koch, A. Ngezahayo and B.N. Chichkov, Femtosecond laser fabricated spike structures for selective control of cellular behavior, Journal of biomaterials applications, 25 (2010) 217-233.

[24] M. Kreisler, W. Kohnen, C. Marinello, H. Götz, H. Duschner, B. Jansen and B. D'Hoedt, Bactericidal effect of the Er: YAG laser on dental implant surfaces: an in vitro study, Journal of periodontology, 73 (2002) 1292-1298.

[25] C. De Giorgi, V. Furlan, A.G. Demir, E. Tallarita, G. Candiani and B. Previtali, Laser micropolishing of AISI 304 stainless steel surfaces for cleanability and bacteria removal capability, Applied Surface Science, 406 (2017) 199-211.

[26] J. Long, P. Fan, D. Gong, D. Jiang, H. Zhang, L. Li and M. Zhong, Superhydrophobic Surfaces Fabricated by Femtosecond Laser with Tunable Water Adhesion From Lotus Leaf to Rose Petal, ACS applied materials \& interfaces, (2015). 
[27] C. Van Oss, M. Chaudhury and R. Good, Monopolar surfaces, Advances in colloid and interface science, 28 (1987) 35-64.

[28] F. Yang, C. Chen, Q. Zhou, Y. Gong, R. Li, C. Li, F. Klämpfl, S. Freund, X. Wu and Y. Sun, Laser beam melting 3D printing of Ti6Al4V based porous structured dental implants: fabrication, biocompatibility analysis and photoelastic study, Scientific reports, 7 (2017).

[29] H.C. Vogely, C. Oosterbos, E. Puts, M. Nijhof, P. Nikkels, A. Fleer, A. Tonino, W. Dhert and A. Verbout, Effects of hydroxyapatite coating on Ti-6 Al-4V implant-site infection in a rabbit tibial model, Journal of Orthopaedic Research, 18 (2000) 485-493.

[30] A. Ben-Yakar, A. Harkin, J. Ashmore, R.L. Byer and H.A. Stone, Thermal and fluid processes of a thin melt zone during femtosecond laser ablation of glass: the formation of rims by single laser pulses, Journal of Physics D: Applied Physics, 40 (2007) 1447.

[31] B.N. Chichkov, C. Momma, S. Nolte, F. Von Alvensleben and A. Tünnermann, Femtosecond, picosecond and nanosecond laser ablation of solids, Applied Physics A, 63 (1996) 109-115.

[32] J. Lehr and A.-M. Kietzig, Production of homogenous micro-structures by femtosecond laser micro-machining, Opt Laser Eng, 57 (2014) 121-129.

[33] M.J.J. Donachie, Heat Treating Titanium and its Alloy. Heat treating progress

(June / July 2001) PP. 47.

[34] O. Kubaschewski and B. Hopkins, Oxidation of metals and alloys, 1962, London, Butterworths. JHD JULY, 577 (1972) 661-662.

[35] C. Langlade, A. Vannes, J. Krafft and J. Martin, Surface modification and tribological behaviour of titanium and titanium alloys after YAG-laser treatments, Surface and Coatings Technology, 100 (1998) 383-387.

[36] A.P. Del Pino, P. Serra and J. Morenza, Coloring of titanium by pulsed laser processing in air, Thin Solid Films, 415 (2002) 201-205.

[37] A.P. Del Pino, J. Fernández-Pradas, P. Serra and J. Morenza, Coloring of titanium through laser oxidation: comparative study with anodizing, Surface and Coatings Technology, 187 (2004) 106-112.

[38] M.V. Diamanti, B. Del Curto and M. Pedeferri, Interference colors of thin oxide layers on titanium, Color Research \& Application, 33 (2008) 221.

[39] S. O'Hana, A.J. Pinkerton, K. Shoba, A.W. Gale and L. Li, Laser surface colouring of titanium for contemporary jewellery, Surf Eng, 24 (2008) 147-153.

[40] E. György, A. Perez del Pino, P. Serra and J. Morenza, Structure formation on titanium during oxidation induced by cumulative pulsed Nd: YAG laser irradiation, Applied Physics A: Materials Science \& Processing, 78 (2004) 765-770.

[41] B. Liu, W. Wang, G. Jiang, X. Mei, K. Wang and J. Wang, Formation of porous structure with subspot size under the irradiation of picosecond laser pulses, Journal of Nanomaterials, 2013 (2013) 11.

[42] L. Li, W. Guo, Z. Wang, Z. Liu, D. Whitehead and B. Luk'yanchuk, Large-area laser nano-texturing with user-defined patterns, Journal of Micromechanics and Microengineering, 19 (2009) 054002.

[43] J. Schille, R. Ebert, U. Loeschner, P. Regenfuss, T. Suess and H. Exner, Micro structuring with highly repetitive ultra short laser pulses, in: Proc. 9th Int'l Symp. Laser Prec. Microfab.(LMP2008), 2008, pp. 08-57.

[44] Y. Li, Z. Cui, W. Wang, C. Lin and H.-L. Tsai, Formation of linked nanostructuretextured mound-shaped microstructures on stainless steel surface via femtosecond laser ablation, Applied Surface Science, 324 (2015) 775-783.

[45] J. Wang and C. Guo, Ultrafast dynamics of femtosecond laser-induced periodic surface pattern formation on metals, Appl Phys Lett, 87 (2005) 251914. 
[46] J. Bonse, J. Krüger, S. Höhm and A. Rosenfeld, Femtosecond laser-induced periodic surface structures, J Laser Appl, 24 (2012) 042006.

[47] J. Parker and R. Siegel, Calibration of the Raman spectrum to the oxygen stoichiometry of nanophase TiO2, Appl Phys Lett, 57 (1990) 943-945.

[48] X. Zhang, L. Wang and E. Levänen, Superhydrophobic surfaces for the reduction of bacterial adhesion, RSC Advances, 3 (2013) 12003-12020.

[49] C.R. Crick, S. Ismail, J. Pratten and I.P. Parkin, An investigation into bacterial attachment to an elastomeric superhydrophobic surface prepared via aerosol assisted deposition, Thin Solid Films, 519 (2011) 3722-3727.

[50] K.A. Whitehead, J. Colligon and J. Verran, Retention of microbial cells in substratum surface features of micrometer and sub-micrometer dimensions, Colloids and Surfaces B: Biointerfaces, 41 (2005) 129-138.

[51] J. Holah and R. Thorpe, Cleanability in relation to bacterial retention on unused and abraded domestic sink materials, Journal of Applied Bacteriology, 69 (1990) 599-608.

[52] D. Timperley, R. Thorpe and J. Holah, Implications of engineering design in food industry hygiene, in: Biofilms - Science and Technology, Springer, 1992, pp. 379-393.

[53] S. Flint and N. Hartley, A modified selective medium for the detection of Pseudomonas species that cause spoilage of milk and dairy products, International Dairy Journal, 6 (1996) 223-230. 
